\title{
Short-term genome evolution of Listeria monocytogenes in a non-controlled environment
}

\author{
Renato H Orsi ${ }^{1}$, Mark L Borowsky ${ }^{2,7}$, Peter Lauer ${ }^{3}$, Sarah K Young2, \\ Chad Nusbaum², James E Galagan ${ }^{2,4}$, Bruce W Birren², Reid A Ivy', Qi Sun ${ }^{5}$, \\ Lewis M Graves ${ }^{6}$, Bala Swaminathan ${ }^{6}$ and Martin Wiedmann*1
}

Address: ${ }^{1}$ Department of Food Science, Cornell University, Ithaca, USA, ${ }^{2}$ Genome Sequencing and Analysis Program, Broad Institute of MIT and Harvard, Cambridge, USA, ${ }^{3}$ Anza Therapeutics, Concord, USA, ${ }^{4}$ Department of Biomedical Engineering and Microbiology, Boston University, USA, ${ }^{5}$ Computational Biology Services Unit, Center for Advanced Computing, Cornell University, Ithaca, USA, ${ }^{6}$ Enteric Diseases Laboratory Branch, Division of Foodborne, Bacterial and Mycotic Diseases, Centers for Disease Control and Prevention, Atlanta, USA and ${ }^{7}$ Department of Molecular Biology, Massachusetts General Hospital, Boston, USA

Email: Renato H Orsi - rho2@cornell.edu; Mark L Borowsky - borowsky@molbio.mgh.harvard.edu; Peter Lauer - plauer@anzatherapeutics.com; Sarah K Young - stowey@broad.mit.edu; Chad Nusbaum - chad@broad.mit.edu; James E Galagan - jgalag@mit.edu;

BruceW Birren - bwb@broad.mit.edu; Reid A Ivy - rai6@cornell.edu; Qi Sun - qisun@tc.cornell.edu; Lewis M Graves - lmg2@cdc.gov; Bala Swaminathan - balas7780@gmail.com; Martin Wiedmann* - mw16@cornell.edu

* Corresponding author

Published: 13 November 2008

BMC Genomics 2008, 9:539 doi:10.1/86/|47|-2164-9-539
Received: 28 April 2008

Accepted: 13 November 2008

This article is available from: http://www.biomedcentral.com/I47I-2/64/9/539

(C) 2008 Orsi et al; licensee BioMed Central Ltd.

This is an Open Access article distributed under the terms of the Creative Commons Attribution License (http://creativecommons.org/licenses/by/2.0), which permits unrestricted use, distribution, and reproduction in any medium, provided the original work is properly cited.

\begin{abstract}
Background: While increasing data on bacterial evolution in controlled environments are available, our understanding of bacterial genome evolution in natural environments is limited. We thus performed full genome analyses on four Listeria monocytogenes, including human and food isolates from both a 1988 case of sporadic listeriosis and a 2000 listeriosis outbreak, which had been linked to contaminated food from a single processing facility. All four isolates had been shown to have identical subtypes, suggesting that a specific $L$. monocytogenes strain persisted in this processing plant over at least 12 years. While a genome sequence for the 1988 food isolate has been reported, we sequenced the genomes of the 1988 human isolate as well as a human and a food isolate from the $\mathbf{2 0 0 0}$ outbreak to allow for comparative genome analyses.

Results: The two L. monocytogenes isolates from 1988 and the two isolates from 2000 had highly similar genome backbone sequences with very few single nucleotide (nt) polymorphisms (I - $8 \mathrm{SNPs}$ /isolate; confirmed by re-sequencing). While no genome rearrangements were identified in the backbone genome of the four isolates, a $42 \mathrm{~kb}$ prophage inserted in the chromosomal comK gene showed evidence for major genome rearrangements. The human-food isolate pair from each 1988 and 2000 had identical prophage sequence; however, there were significant differences in the prophage sequences between the 1988 and 2000 isolates. Diversification of this prophage appears to have been caused by multiple homologous recombination events or possibly prophage replacement. In addition, only the 2000 human isolate contained a plasmid, suggesting plasmid loss or acquisition events. Surprisingly, besides the polymorphisms found in the comK prophage, a single SNP in the tRNA Thr-4 prophage represents the only SNP that differentiates the 1988 isolates from the 2000 isolates.

Conclusion: Our data support the hypothesis that the 2000 human listeriosis outbreak was caused by a L. monocytogenes strain that persisted in a food processing facility over 12 years and show that genome sequencing is a valuable and feasible tool for retrospective epidemiological analyses. Short-term evolution of $L$. monocytogenes in non-controlled environments appears to involve limited diversification beyond plasmid gain or loss and prophage diversification, highlighting the importance of phages in bacterial evolution.
\end{abstract}




\section{Background}

Experimentally evolved lineages of bacteria have provided important data on mechanisms involved in short-term bacterial evolution and adaptation [1-3] in simple controlled environments. However, experiments in controlled environments cannot represent all forces contributing to evolution in non-controlled settings and natural environments. Important differences between experimental and natural bacterial populations include (i) population sizes that are much greater in experimental populations than in a natural population; (ii) generation times that are probably much shorter in an experimental population than in a natural population; and (iii) absence of donors of genetic materials, which allow for rapid diversification via horizontal gene transfer (e.g., other bacteria, bacteriophages). In addition, while experimental populations experience selective pressures that are usually low in number but high in intensity, natural populations encounter many selective pressures imposed by physical (e.g., temperature), chemical (e.g., pH), and biological (e.g., phages and other microbial organisms) variables, which differ in intensity and vary over time. The strong selective pressure provided by controlled environments often results in parallel evolution of replicates under the same conditions $[1,4,5]$. For example, 12 Escherichia coli populations that originated from the same parent strain all showed substitutions in the same candidate genes after they were cultured for 20,000 generations under identical conditions [5].

Listeria monocytogenes is a gram-positive, facultative intracellular foodborne pathogen that causes listeriosis in humans and many mammalian and avian species [6,7]. Human listeriosis is a rare but severe disease; an estimated 2,500 human invasive listeriosis cases including 500 deaths occur annually in the United States [8]. The vast majority of human listeriosis cases are caused by foodborne transmission [8]. A common source of food contamination appears to be transmission of L. monocytogenes present in processing plant environments to food products after they have been heat processed [9]. L. monocytogenes is ubiquitously distributed in the environment. It can grow under a wide range of environmental conditions, including temperatures ranging from $0.4^{\circ} \mathrm{C}$ to $45^{\circ} \mathrm{C}[10,11]$ and $\mathrm{pH}$ ranging from 4 to $9.6[12,13]$. Consequently, it is difficult to control L. monocytogenes in food processing environments. Although food processing facilities and equipment are regularly cleaned and sanitized, persistence of specific $L$. monocytogenes subtypes, over time periods ranging from a few months to more than five years, has been documented for a number of food processing facilities [14-17].

It is also common for several $L$. monocytogenes subtypes to co-exist in the same food processing facility [15-20].
While use of molecular subtyping methods, such as pulsed-field gel electrophoresis (PFGE), has been critical in listeriosis outbreak investigations and surveillance, interpretation of subtyping data sometimes remains a challenge as isolates may diversify rapidly (e.g., due to plasmid losses, yielding different PFGE patterns [21]) and as epidemiologically unrelated strains may share identical PFGE patterns $[22,23]$. Consequently, there is a need to better understand L. monocytogenes diversification in noncontrolled environments and to develop improved subtyping approaches that can be used in follow-up studies to routine subtyping using PFGE.

In 1988, a sporadic case of human listeriosis in Oklahoma, USA was linked to the consumption of L. monocytogenes contaminated turkey franks produced in a food processing facility in Texas, USA [24]. Twelve years later, in 2000, a multi-state listeriosis outbreak, which caused illnesses in 29 persons in 11 US states (including 4 deaths), was linked to consumption of deli turkey meat produced in the same processing facility that was linked to the 1988 listeriosis case [25,26]. Phenotypic and genotypic typing showed that human and food isolates from both episodes belonged to the same serotype $(1 / 2 \mathrm{a})$, were slow rhamnose fermenters (a rare phenotype for $1 / 2 \mathrm{a}$ isolates), and were indistinguishable by ribotyping (all isolates were ribotype DUP-1053A [27]) and PFGE [26]. The PFGE type for these isolates (type 25, as reported by [27]) was only found once among a set of $495 \mathrm{~L}$. monocytogenes isolates previously characterized by PFGE [22], indicating that this specific strain represents a combination of genetic and phenotypic characteristics that is rare. While re-introduction of this strain in the processing plant from the outside environment represents a possibility, the rarity of this strain and the fact that ready-to-eat food processing plants typically implement practices to prevent introduction of microbial organisms suggests that persistence of a single L. monocytogenes strain in this facility for at least 12 years [14] is the most likely explanation for the observations detailed above. The genome sequence of a food isolate (F6854) from the 1988 episode has previously been determined using automated Sanger sequencing [28]. We sequenced the genome of the corresponding human isolate from the 1988 episode as well as the genomes of a human and a food isolate from the 2000 outbreak. Sequence comparisons of these genomes enabled us to characterize $L$. monocytogenes evolution during short-term survival in a non-controlled non-host environment and to determine the value of full genome sequencing as a subtyping approach in follow-up studies to outbreak investigations. 


\section{Results \\ Genome sequencing of three L. monocytogenes isolates by 454 pyrosequencing}

The human isolate from the 1988 listeriosis case (F6900) and a human (J0161) and a food (J2818) isolate from the 2000 multi-state listeriosis outbreak in the US (Table 1) were sequenced using the 454 GS20 Genome Sequencer (454 Life Sciences, Branford, CT), which uses the "sequencing by synthesis" technology [29]. Chromosomal sequences ranged from $2.96 \mathrm{Mb}$ to $2.97 \mathrm{Mb}$, the sequencing depth ranged from 24 to 29.15 -fold. The sequenced genomes captured between 93.79 and $96.08 \%$ of the EGD-e reference genome (Table 2).

In addition to the chromosomal sequences, a plasmid sequence was found in the 2000 human isolate (J0161). This plasmid represented two non-overlapping contigs of $69,915 \mathrm{bp}$ and $12,763 \mathrm{bp}$. These two plasmid contigs showed a very high level of nucleotide identity (>99\%) with pLM80, an approx. $80 \mathrm{~kb}$ plasmid previously reported in the serotype $4 \mathrm{~b}$ (lineage I) strain H7858 [28]. The two plasmid contigs included all 95 ORFs previously identified in pLM80 [28]. Genes found in the plasmid contigs included at least 11 genes annotated as transposon genes in pLM80 and two genes associated with cadmium resistance. The observation that this plasmid was only sequenced in the 2000 human isolate (J0161) suggests either a loss of the plasmid in the other isolates (during propagation in the food processing plant, the food or the human host for the 1988 isolate or during isolation) or an acquisition of this plasmid in the 2000 human isolate.

\section{Genome alignment and polymorphism analyses}

To identify genomic differences between the human and food isolate from the 1988 case as well as a food and human isolate from the 2000 outbreak, we aligned the 4 genomes using TBA (Threaded-Blockset Aligner) [30] and refined this alignment using MUSCLE [31]. The refined alignment of the four genomes had a total length of $2,922,773$ bp (including gaps) (Figure 1). The aligned sequences for each genome ranged from 2,921,243 to $2,921,655$ (Table 2). As between $1.2 \%$ and $1.7 \%$ of the genome sequences for each isolate could not be included in the alignment, it is possible that the four isolates con- tain some differences in addition to those detailed below. Regions not included in the alignment most likely represent regions not sequenced in one or more genomes, deletions/insertions, or genome fragments replaced by a nonhomologous sequence (i.e., within the comK prophage). Specifically, while the length of the comK prophage sequence ranged from 38,876 to 42,001 bases in the four isolates (Table 2), the $\operatorname{comK}$ prophage alignment (including gaps) was only $28,886 \mathrm{bp}$, indicating extensive diversification including presence of non-homologous prophage sequences in the different isolates (as described in detail below). This difference represents $25 \%$ of the non-aligned sequences in the whole genome alignment, although this prophage represents less than $2 \%$ of the genome size.

The final alignment was divided in three distinct nonoverlapping alignments representing (i) the $\operatorname{comK}$ prophage $(28,886 \mathrm{bp})$, (ii) the tRNA Thr-4 prophage (34,703 bp), and (iii) the backbone sequence $(2,859,184$ bp) representing the rest of the chromosomal sequence. Identification of polymorphisms and recombination were carried out separately for each alignment. The comK prophage alignment had 1,274 polymorphic sites that differentiated the two 1988 isolates from the two 2000 isolates; at all of these sites, the isolates from the same year were identical to each other. In contrast, the tRNA Thr- 4 prophage alignment had one confirmed polymorphic site, which differentiated the 1988 isolates from the 2000 isolates; this site represents a nonsynonymous transversion (Table 3). Surprisingly, besides the polymorphisms found in the comK prophage, the polymorphism in the tRNA Thr-4 prophage represents the only SNP that differentiates the 1988 isolates from the 2000 isolates.

Among the 11 confirmed polymorphisms in the backbone sequence (excluding the comK and Thr-4 prophage) of the J0161 subculture sequenced at Broad, eight were specific to J2818 (2000 food isolate), one was specific to F6900 (1988 human isolate), and one was specific to J0161 (2000 human isolate) (Table 3). In addition, one polymorphism (SNP \#3; Table 3) was present in the J0161 subculture sequenced at Broad, but was not found in the J0161 subculture used for re-sequencing at Cornell (see "Methods"). Among the eight polymorphisms specific to

Table I: Human and food isolates from the 1988 sporadic listeriosis case and the 2000 outbreak used for genome comparisons

\begin{tabular}{lcccc}
\hline Isolates & Date sample/specimens was collected & Source & Genome sequencing method used & Source of genome sequence \\
\hline F6854(1) & December 1988 & Food & Sanger & [28] \\
F6900 & December 1988 & Human & 454 & This study \\
J2818 & Fall 2000 & Food & 454 & This study \\
J0161 & October 2000 & Human & 454 & This study
\end{tabular}

(I)The F6854 genome sequence represents one pseudomolecule in which gaps between the contigs were closed with random sequences using the fully sequenced genome of EGD-e as a reference [28]. 
Table 2: Assembly quality metrics for strains sequenced in this study

\begin{tabular}{|c|c|c|c|c|}
\hline Strain & F6900 & J016I & $\mathrm{J} 2818$ & FSL JI-194 \\
\hline Contig N50(1) & $434 \mathrm{~kb}$ & $148 \mathrm{~kb}$ & $167 \mathrm{~kb}$ & $156 \mathrm{~kb}$ \\
\hline Total contigs & 35 & 49 & 38 & 43 \\
\hline Assembly size & $2.96 \mathrm{Mb}$ & $2.97 \mathrm{Mb}$ & $2.97 \mathrm{Mb}$ & $2.93 \mathrm{Mb}$ \\
\hline Aligned sequence length $(n t)^{(2)}$ & $2,921,655$ & $2,921,243$ & $2,921,377$ & - \\
\hline comK prophage sequence length (number of contigs) ${ }^{(3)}$ & 38,876 bp (5) & 41,349 bp (4) & 42,001 bp $(2)$ & 42,189 bp (I) \\
\hline Contigs to capture $90 \%$ of assembly & II & 19 & 19 & 19 \\
\hline Fraction bases Q40(4) & $99.5 \%$ & $99.7 \%$ & $99.8 \%$ & $99.7 \%$ \\
\hline Fraction reference covered & $95.97 \%$ & $95.97 \%$ & $96.08 \%$ & $93.79 \%$ \\
\hline Assembled coverage & $25 \times$ & $30 x$ & $24 \times$ & $22 \times$ \\
\hline
\end{tabular}

(I) Length-weighted median that describes the contig size in which at least half the bases reside.

(2) Length of each sequence in the refined alignment containing the 1988 and 2000 isolates. The length for F6854 is 2,92I,388 nt.

(3) Sequenced length of the prophage inserted into comK for each isolate/strain. The length for F6854 is 4I,259 nt.

(4) As reported by 454 assembly software.

the 2000 food isolate (J2818, Table 3), three fall in intergenic regions and five fall in coding sequences, including one representing a synonymous change and four representing nonsynonymous changes (Table 3). The 2000 human and food isolates thus differ from each other in four nonsynonymous sites, including one substitution (SNP 10; Table 3) in addB, which encodes a protein that is part of the enzyme AddAB [32,33]. AddAB is analogous to E. coli RecBCD, which is responsible for processing double-stranded breaks in the chromosome $[33,34]$.

\section{Distribution of the human outbreak isolate specific SNPs and plasmid sequences among other outbreak associated human clinical isolates}

As the 2000 human and food isolates differed by 9 SNPs, we identified additional human isolates associated with the 2000 outbreak to validate these SNPs; unfortunately no additional food isolates associated with this outbreak were available for SNP validation. Nine isolates with ribotype DUP-1053A (representing the ribotype of the 1988 and 2000 food and human isolates) obtained between August and November of 2000 from human clinical cases in Ohio, Michigan and New York were found to be slow rhamnose-fermenters. These isolates were also found, by PFGE using ApaI and AscI for restriction of DNA, to be indistinguishable from each other and from the 1988 and 2000 human and food isolates sequenced. As these results strongly suggested that these nine isolates were from humans that were infected as part of the 2000 outbreak, we screened these isolates for the 12 confirmed polymorphisms identified among the genome sequences for the human and food isolates from the 1988 case and the 2000 outbreak as well as for the presence of two plasmid-specific sequences. All 9 isolates were positive by PCR for both plasmid sequences, indicating that the plasmid found in J0161 is present in most other human isolates associated with this outbreak. None of these nine human isolates had any of the polymorphisms specific to F6900 (1988 human isolate) or J2818 (2000 food isolate).
Furthermore, none of the nine isolates shared the one SNP specific to the subculture of the 2000 human isolate (J0161) that was sequenced at Broad (SNP 3; Table 3), but that was not found in the J0161 subculture that was used for re-sequencing at Cornell, supporting the hypothesis that this polymorphism arose during laboratory passage of the J0161 subculture sequenced at Broad. Nevertheless, all nine human isolates showed (i) nt sequences identical to J0161 (the sequenced 2000 human isolate) at the eight sites that carry unique SNPs in the 2000 food isolate (J2818), (ii) the SNP unique to the 2000 human isolate J0161 (SNP 2; Table 3) as well as (iii) the tRNA Thr-4 prophage SNP (SNP 12; Table 3) that differentiates the 1988 isolates from the 2000 isolates. SNP 2 thus does not represent a random mutation unique to the sequenced human isolate from the 2000 outbreak (e.g., mutation that arose during passage or infection), but was found in all human clinical isolates surveyed from this outbreak.

\section{Intracellular growth assays of the $\mathbf{2 0 0 0}$ human and food isolates}

While it is unlikely that any of the few nonsynonymous substitutions observed would affect the fitness of L. monocytogenes strains tested here, we performed preliminary experiments to test whether the nonsynonymous sites differentiating the 2000 human and food isolates (may affect the ability of the 2000 human and food isolates to multiply inside macrophage cells. We specifically surmised that the nonconservative Trp $\rightarrow$ Cys change in addB (i.e., SNP 10 , Table 3 ) could alter the function of the enzyme AddAB $[32,33]$, which is analogous to E. coli RecBCD [33,34]. As RecBCD deficient $E$. coli mutants have been shown to be more susceptible to oxidative DNA damage [35]; we hypothesized that the 2000 food and human isolates may differ in their ability to survive inside activated macrophages (i.e., J774 cells stimulated with LPS) where they may be exposed to oxidative stress. We used FSL R2-499 (a subculture of J0161 confirmed as having SNP 10 and thus encoding the same $a d d B$ allelic variant as J0161) and the 


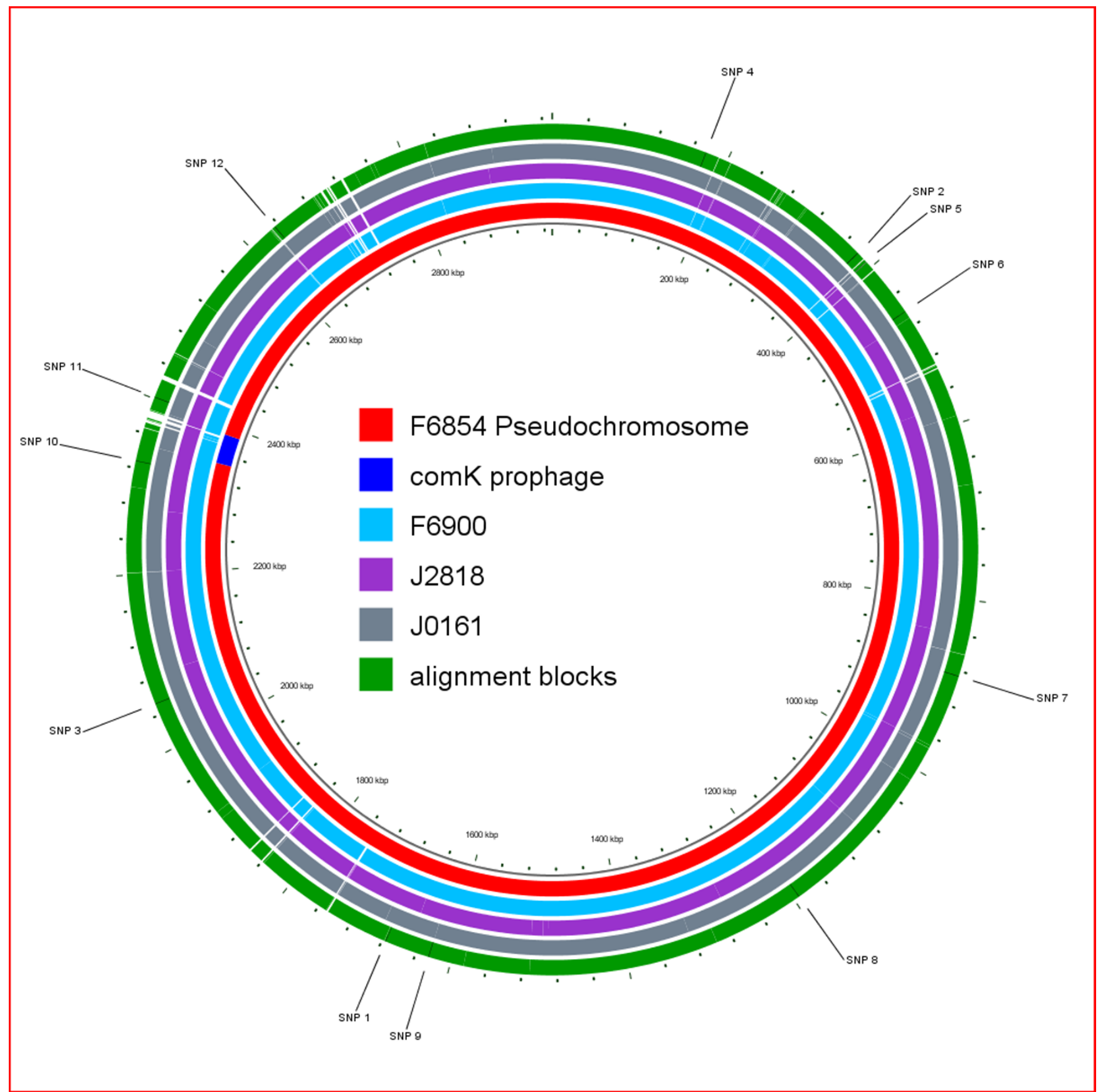

\section{Figure I}

Circular map of genomes analyzed. The $\mathrm{F} 6854$ pseudochromosome is shown in red except for the comK prophage which is shown in blue. The genomic contigs of F6900, J0I6I and J28I 8 are shown in blue, purple and gray, respectively. The blocks of aligned sequence in the refined alignment of F6854, F6900, J016I and J28I 8 are shown in green. All sequences were aligned against the pseudochromosome of F6854, which was used as the reference.

2000 food isolate $\mathrm{J} 2818$ for these experiments. As no apparent difference in intracellular growth of these two strains was observed when the strains were initially characterized in separate intracellular growth assays (Additional file 1), we performed triplicate competition experiments by infecting $\mathrm{J} 774$ cells with both strains simultaneously; competition assays like this typically provide for more sensitive means to identify whether one strain has a competitive advantage over another strain in a given environment $[36,37]$. In the competitive intracel- 
Table 3: Confirmed single nucleotide polymorphisms found among clinical and food isolates associated with the 1988 sporadic listeriosis case and the 2000 listeriosis outbreak

\begin{tabular}{|c|c|c|c|c|c|}
\hline SNP no. & Position( $($ ) & $\begin{array}{c}\text { Locus } \\
(\text { LMOf6854)(2) }\end{array}$ & Annotation & Nucleotide change & Amino acid change \\
\hline \multicolumn{6}{|c|}{ SNPs unique to isolate F6900 (1988 human isolate) } \\
\hline I & 1675779 & $1688 \leftrightarrow 1688.1$ & $\begin{array}{c}\text { trpE, anthranilate synthase component I } \leftrightarrow \text { alcohol } \\
\text { dehydrogenase, iron-containing }\end{array}$ & $A \rightarrow G$ & Noncoding \\
\hline \multicolumn{6}{|c|}{ SNPs unique to isolate $\mathrm{J0} 16 \mathrm{I}$ (2000 human isolate) } \\
\hline 2 & 378489 & $0351 \rightarrow 0352$ & $\begin{array}{l}\text { nikkomycin biosynthesis domain protein } \rightarrow \mathrm{N} \text { - } \\
\text { acetylmannosamine- 6-phosphate epimerase }\end{array}$ & $\mathrm{C} \rightarrow \mathrm{T}$ & Noncoding \\
\hline $3(3)$ & 2053116 & $2071 \leftarrow 2072$ & $A B C$ transporter $\leftarrow D N A-b i n d i n g$ response regulator & $\mathrm{T} \rightarrow \mathrm{C}$ & Noncoding \\
\hline \multicolumn{6}{|c|}{ SNPs unique to isolate $J 2818$ (2000 food isolate) } \\
\hline 4 & $|7472|$ & $0150 \rightarrow 0150.1$ & $\begin{array}{c}\text { oligopeptide } A B C \text { transporter } \rightarrow \text { conserved } \\
\text { hypothetical protein }\end{array}$ & $\mathrm{T} \rightarrow \mathrm{C}$ & Noncoding \\
\hline 5 & 392427 & $0365.1 \rightarrow 0367$ & $\begin{array}{l}\text { conserved hypothetical protein } \rightarrow \text { inll, cell wall } \\
\text { surface anchor family protein }\end{array}$ & $\mathrm{G} \rightarrow \mathrm{A}$ & Noncoding \\
\hline 6 & 462089 & 0447 & Phosphoenolpyruvate synthase & $\mathrm{G} \rightarrow \mathrm{A}$ & I I 3 Pro $\rightarrow$ I | $3 \mathrm{Ser}(4)$ \\
\hline 7 & 885898 & $0876 \leftrightarrow 0877$ & Membrane protein $\leftrightarrow$ transposase OrfA, IS3 & $A \rightarrow G$ & Noncoding \\
\hline 8 & 1193390 & 1203 & $\begin{array}{c}\text { pduP, CoA-dependent propionaldehyde } \\
\text { dehydrogenase }\end{array}$ & $\mathrm{C} \rightarrow \mathrm{A}$ & 359 Pro $\rightarrow 359 \mathrm{Thr}^{(5)}$ \\
\hline 9 & 1625104 & 1635.1 & RDD family & $\mathrm{G} \rightarrow \mathrm{T}$ & $2 \mathrm{Ala} \rightarrow 2 \mathrm{Asp}(5)$ \\
\hline 10 & 2327842 & 2332 & addB, ATP-dependent nuclease, subunit B & $\mathrm{C} \rightarrow \mathrm{A}$ & $388 \mathrm{Trp} \rightarrow 388 \mathrm{Cys}(5)$ \\
\hline 11 & 2401731 & 2435.1 & Unknown function & $\mathrm{G} \rightarrow \mathrm{A}$ & Synonymous \\
\hline \multicolumn{6}{|c|}{ SNP differentiating the two 1988 isolates from the two 2000 isolates } \\
\hline 12 & 2635720 & 2659 & Phage tail component, $\mathrm{N}$-terminal domain & $\mathrm{A} \rightarrow \mathrm{T}$ & $4|9| l e \rightarrow 4 \mid 9$ Leu $^{(5)}$ \\
\hline
\end{tabular}

(I)Nucleotide position in the full alignment of F6854, F6900, J016I and J28I8; this alignment is available at http://www.foodscience.cornell.edu/cals/ foodsci/research/labs/wiedmann/links/orsi 2008-bmc-genomics.cfm

(2)Arrows indicate direction of genes in the chromosome, e.g. 035I $\rightarrow 0352$ means that the polymorphism falls downstream to LMOf6854_035I and upstream to LMOf6854_0352. $\leftrightarrow$ means that the polymorphism falls upstream to both genes (possible of genes are transcribed divergently). (3)SNP \#3 is not present in FSL R2-499, the J016I subculture sent from CDC to the Cornell Food Safety Laboratory (FSL), and is also not present in nine other human isolates linked to the 2000 listeriosis outbreak, which were also tested; this SNP thus appears to have arisen during laboratory passage of the $1016 \mathrm{I}$ clone sequenced at the Broad Institute.

(4)This nonsynonymous change falls within the phosphoenolpyruvate/pyruvate binding domain (aa 3 to aa 34 I)

(5) These nonsynonymous changes fall into regions that have no specific predicted domains

lular growth assay the relative recovery of both isolates after $9 \mathrm{~h}$ of intracellular growth did not differ significantly $(P>0.05$; chi-square test); overall, 16 and 14 colonies, respectively, with the J2818 and the J0161 addB allelic type were recovered $(3 / 10,7 / 10$, and $6 / 10$ isolates carried the J2818 addB allelic type in replicates 1,2 , and 3, respectively). While these data suggest that the mutations that differentiate the two 2000 isolates do not affect the intracellular growth capabilities, of these isolates, in activated J774 macrophage cells, future phenotypic and animal experiments would be needed to further test whether the 2000 human and food isolate genotypes differ in their fitness. As no data on the effect of an L. monocytogenes addB null mutation are available, it is unclear which physiological functions may be affected by nonsynonymous mutations in this gene. Future experiments thus should involve characterization of an $a d d B$ null mutant before conducting additional phenotypic and animal experiments to determine the effect of the observed nonsynonymous mutation in $a d d B$ and/or other nonsynonymous mutations differentiating the 2000 human and food isolates.

\section{Estimation of congruence between observed low mutation} rate and known mutation rates in bacterial populations Overall, we only found a single synonymous nucleotide difference (SNP 11; Table 3) between the 2000 food isolate (J2818) and the 1988 isolates and no synonymous nucleotide difference between the 2000 human isolate (J0161) and the 1988 isolates. In order to determine whether this low number of synonymous changes is consistent with previously reported mutation rates for bacteria, we calculated the estimated number of generations between the 1988 isolates and the 2000 food isolates (J2818) using previously reported mutation rates $[2,3,38]$, including $3.30-4.50 \times 10^{-10}$ per bp per generation for experimental Myxococcus xanthus populations [3] and 1.44 $\times 10^{-10}$ per bp per generation for experimental E. coli populations [2]. Ochman et al. [38] estimated a mutation rate of $4.50 \times 10^{-9}$ per bp per year (approximately $2.25 \times 10^{-11}$ per bp per generation assuming $\sim 200$ generations per year) for natural populations of E. coli and $8.20 \times 10^{-9}$ per bp per year (approximately $2.05 \times 10^{-10}$ per bp per generation assuming 40 generations per year) for natural pop- 
ulations of Buchnera. The number of generations was calculated as the (number of synonymous substitutions, i.e., 1$]) /\left[\left(\right.\right.$ number of synonymous sites, i.e., $\left.5.65 \times 10^{5}\right) \times$ (mutation rate)]. Using the two extremes of the suggested mutation rates $\left(2.25 \times 10^{-11}\right.$ and $4.50 \times 10^{-10}$ per bp per generation) we estimated that between 3,933 and 78,666 generations separated the 1988 isolates from the 2000 isolates. Assuming a 12 year time span between the two sets of isolates, these mutation rates translate into 328 and 6,556 generations per year $(0.90-17.96$ generations per day), yielding a generation time ranging from 1.34 to 26.67 hours. The generation time estimate $(1.34 \mathrm{~h})$ based on the low mutation rate $\left(2.25 \times 10^{-11}\right.$ mutations per bp per generation) proposed for natural populations of $E$. coli [38] is only about 2-fold longer than the estimated generation time for $L$. monocytogenes in rich media broth at $30^{\circ} \mathrm{C}(0.7 \mathrm{~h})[39]$.

Other L. monocytogenes generation times reported were $14.2 \mathrm{~h}$ (in rich-media at $4{ }^{\circ} \mathrm{C}$ [39]) and $111.3 \mathrm{~h}$ (for $L$. monocytogenes in soil exposed to temperatures fluctuating between $-29^{\circ} \mathrm{C}$ to $12^{\circ} \mathrm{C}$ [40]). We thus propose that a mutation rate closer to $4.50 \times 10^{-10}$ (as estimated from an experimental population of M. xanthus [3]) is more likely to represent the mutation rate for $L$. monocytogenes, as a generation time of approx $24-28 \mathrm{~h}$ seems plausible for $L$. monocytogenes in natural environments. Under this mutation rate, generation time, and assuming a Poisson distribution, the probability of observing zero or one synonymous substitution is roughly the same ( $36.8 \%)$, which is consistent with the observation that the 2000 food isolate (J2818) differed from the 1988 isolates by one synonymous change, while the 2000 human isolate (J0161) showed no synonymous changes as compared to the 1988 isolates. In conclusion, the low rate of mutations observed for the isolates studied here is thus clearly within the range expected based on previously reported mutation rates for other bacteria.

\section{Comparative analyses of comK prophage sequences in the 1988 and 2000 isolates}

As the comK prophage in the 2000 isolates showed considerable divergence from the comK prophage in the 1988 isolates (1,274 nt differences between the 1988 and 2000 prophage sequences), further analyses were performed on the $\operatorname{comK}$ prophage sequences. Initial BLAST searches against (i) the F6854 genome, (ii) genome sequences deposited in GenBank [41], and (iii) genome sequences in the L. monocytogenes database at the Broad Institute [42] found that the following prophages showed the highest similarity to the 2000 isolate prophage sequence: (i) the comK prophage sequence in L. monocytogenes FSL J1-194 (BLAST score of $2.23 \times 10^{4} \mathrm{bits}$ ), (ii) the $\operatorname{comK}$ prophage in F6854 (the 1988 human isolate; $1.88 \times 10^{4}$ bits), (ii) the phage A500 (1.03 × $10^{4}$ bits) (GenBank accession
DQ003637), (iii) the comK prophage in EGD-e $(1.01 \times$ $10^{4}$ bits) [43], and (iv) the phage A118 (8.82 $\times 10^{3}$ bits) [44]. Additionally, BLAST searches of the individual genes in the $\operatorname{comK}$ prophage against these same databases, showed that 35 of the 65 genes in the 2000 isolates showed the best match with genes in the FSL J1-194 prophage (Additional file 2); 14 and 11 genes in the 2000 isolates showed the best match with genes from the phage A118 and the EGD-e comK prophage, respectively. While these data suggest that diversification of the comK prophage in the 2000 isolates does not represent a prophage replacement with a sequenced prophage, replacement could have occurred with a prophage not represented in the available nucleotide sequence databases.

To determine whether recombination events could have contributed to the diversification of the comK prophage, recombination analyses were performed on an alignment of the four $\mathrm{comK}$ prophage sequences for the 1988 and the 2000 isolates and the prophage most closely related to the comK prophage in the 2000 isolates (i.e., the $\operatorname{comK}$ prophage in isolate FSL J1-194). Sawyer's test provided evidence for recombination among the five prophage sequences in the alignment (i.e., inner fragments, $P<$ 0.0001 ) as well as for recombination with sequences not included in this alignment (i.e., outer fragments, $P<$ 0.0001). Overall, five inner recombination events involving the comK prophage in the two 2000 isolates and FSL J1-194 were initially identified. Visual analysis of the prophage sequences suggests at least three independent recombination events in the two 2000 isolates, relative to the two 1988 isolates; for these three recombinant regions (marked as R1, R2, and R3 in Figure 2) the prophage sequences in two 2000 isolates were more similar to FSL J1-194 than to the prophage sequences in the two 1988 isolates (Figure 2). Analyses of nt identities between the 1988 and 2000 isolates and FSL J1-194 for all individual ORFs in the comK prophage (Additional file 2), also supported that extensive recombination occurred in this prophage. While 15 genes showed $100 \%$ identity between the 1988 and 2000 prophage genomes (e.g. LMOf6854_2341.9; Additional file 2), 24 other genes showed identities < 95\% between the 1988 and 2000 prophage genomes and $100 \%$ identity between the 2000 isolates and FSL J1-194 (e.g. LMOf6854_2352.2; Additional file 2), suggesting introduction of these genes into the ancestor of the 2000 isolates from a phage or prophage sequence closely related to that found in FSL J1194. Eleven prophage genes in the two 2000 isolates showed $<98 \%$ identity to the corresponding prophage sequence in the 1988 isolates and a best match with a sequence other than that of FSL J1-194 (e.g. LMOf6854_2371; Additional file 2), suggesting introduction from a distinct phage or prophage genotype. 


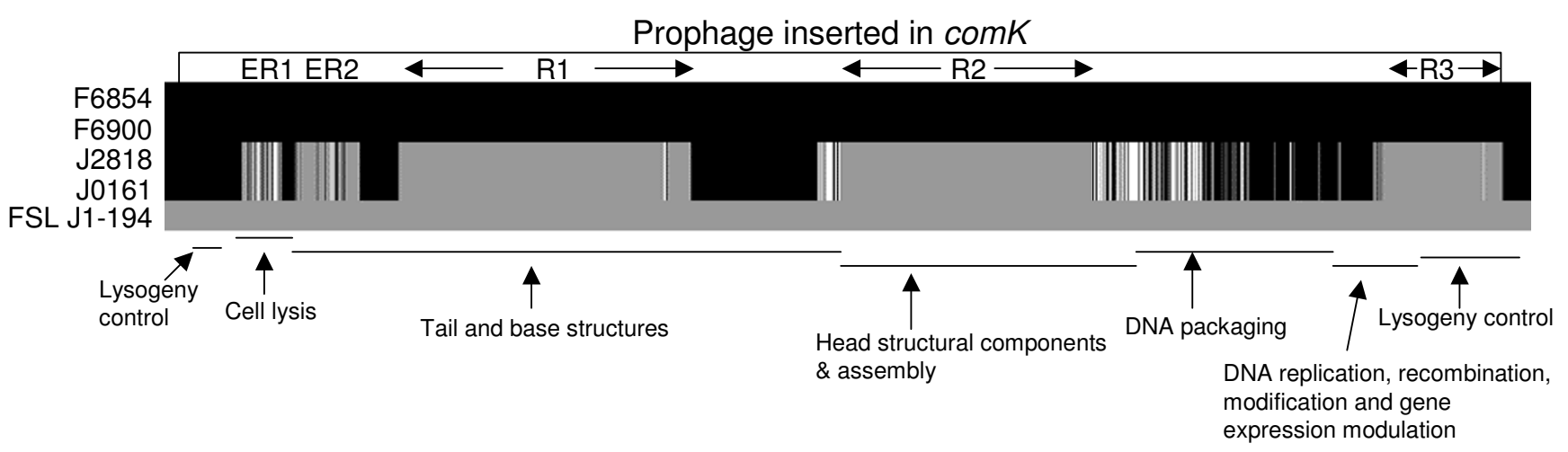

Figure 2

Schematic of recombination events in comK prophage. The figure represents an alignment of the 1892 polymorphic sites in the comK prophage (including coding and non-coding regions) as well as 13 polymorphic sites immediately upstream the prophage and 4I polymorphic sites immediately downstream of the prophage. Sites representing nt residues found in F6854 and F6900 (I 988 isolates) are shown in black and sites representing nt residues found in FSL JI- I94 (a L. monocytogenes serotype $\mathrm{I} / 2 \mathrm{~b}$ isolate with the comK prophage most closely related to the prophage found in the 2000 isolates) are shown in gray. The $n t$ sites in J016 I and J28I8 (2000 isolates) are shaded so that nt identical to the 1988 isolates are in black, nt identical to FSL JI-I94 are in gray, and nt that match neither the 1988 isolates nor FSL JI-I94 are in white. Apparent darker shades of gray in this figure represent adjacent sites with black and gray or white. RI, R2, and R3 (recombination I to 3) represent three main recombinant blocks that were likely introduced from a lineage I strain similar to FSL JI-I94 into a descended of the I988 isolates, yielding the 2000 isolate genotype. The two shorter mixed gray and white blocks at the 5' end, marked as ERI and ER 2 (ER = external recombination) are likely to have been introduced from a $L$. monocytogenes genotype not included in this alignment ("external") into a descendent of the 1988 isolates.

For 18 genes present in the comK prophage of the 1988 isolates (i.e., F6854 and F6900), no homologues were identified in the genomes of the 2000 isolates; 15 of these genes appear to have been replaced in the 2000 isolates by non-homologous genes (Additional file 2). These deletions and replacements in the 2000 isolates are likely consequences of recombination events that integrated or replaced large sequences, as supported by the observation that some observed gene deletions or replacements were located in large recombinant fragments identified by Sawyer's test. For example, the eight adjacent genes LMOf6854_2352.2 to LMOf6854_2360.1 found in the 1988 isolates appear to have been replaced by a block of seven genes in the 2000 isolates (Sawyer's tests identified a recombinant fragment, which corresponds to this replacement event). Two of these eight genes present in the 1988 isolates (LMOf6854_2352.6 and LMOf6854_2352.7) show no homology to the genes present in the 2000 prophage (Additional file 2).

\section{Discussion}

Determination of genome sequences for three L. monocytogenes isolates obtained from foods and human listeriosis cases linked to a single food processing facility, in conjunction with a previously reported genome sequence for a food isolate linked to the same facility [28], provided a unique resource to gain insight into the short-term evolu- tion of L. monocytogenes in non-controlled environments. Overall, our data indicate that short term evolution of $L$. monocytogenes in natural non-controlled environments involves limited diversification of the genomic backbone, but can involve considerable phage-mediated diversification as well as plasmid loss or gain. In addition, our genome sequencing data support that a human listeriosis outbreak that occurred in 2000 in the US was caused by a L. monocytogenes strain that is likely to have persisted in a food processing plant over at least 12 years, supporting the utility of genome sequencing for high resolution follow-up studies in disease outbreak investigations.

\section{Short term evolution of L. monocytogenes in natural environments can involve considerable phage mediated diversification and loss or gain of plasmids}

While a few singletons (i.e., single base differences found in only one isolate) were observed in the genome backbone of the two 1988 and the two 2000 isolates, the only polymorphisms that differentiate the 1988 isolates from the 2000 isolates fall within the two prophages inserted into $\operatorname{comK}$ and tRNA-Thr-4. While the tRNA-Thr-4 prophage region showed only one SNP that differentiated the 1988 and 2000 isolates, the com $K$ prophage region differs considerably between the two 1988 and the two 2000 isolates. Our data suggest that multiple recombination events lead to diversification of the $\operatorname{comK}$ prophage, 
although the occurrence of a single prophage replacement event cannot be excluded. Recombination events seem to have replaced a number of phage genes (including several genes that were annotated as encoding proteins with essential roles in the lytic cycle) with allelic variants or non-homologous genes. For example the gene encoding the major capsid in the 1988 isolates (LMOf6854_2352.7) was replaced with a non-homologous major capsid gene (LMPG_02241.2) in the 2000 isolates. Mechanistically, the observed recombination events in the comK prophage most likely occurred through infection with one or more phages in one or more cells of the 1988 genotype, followed by subsequent recombination or phage replacement. In addition to diversification of the integrated prophage genomes observed here, it has been well documented that phages can be vectors for horizontal transfer of genes located in the genome backbone [45] and that phages are capable of generalized transduction in L. monocytogenes [46]. While we did not find any evidence for horizontal gene transfer outside the prophage region in the isolates studied here, horizontal gene transfer in genes in the backbone genome has been well documented in L. monocytogenes [47-49]. While very little is known about the frequency of phage insertion and phage transduction in bacteria in natural environments, Hodgson [46] reported that rates of phage transduction of Listeria under laboratory conditions ranged from about 1 to 300 transductants per $10^{7} \mathrm{PFU}$. In conclusion, while short term evolution of L. monocytogenes in natural environments involves limited diversification of the genomic backbone, phage-mediated genetic changes appear to be major mechanisms for diversification and evolution of $L$. monocytogenes during short evolutionary time frames. This is particularly interesting as there is no evidence for phageencoded virulence genes in Listeria, unlike for a number of other pathogens where phage mediated transfer and diversification of virulence genes appear to represent an important mechanism for diversification.

Our data are consistent with the overall idea that bacteriophages play multiple important roles in the evolution of bacterial populations in natural environments, including (i) providing selective pressure on bacterial populations (e.g., [50-52]) and (ii) providing a mechanism for rapid horizontal exchange of genetic material (e.g., [53]). Contributions of bacteriophages to genetic diversification also have been well characterized in different pathogenic and non-pathogenic bacterial species. For example, the $V$. cholerae CTX genetic element represents the genome of a lysogenic bacteriophage, which carries the genes for cholera toxin [53]. This lysogenic phage can be induced in toxigenic strains and the resulting phage particle appears to be able to transduce non-toxigenic $V$. cholerae [54]. Similarly, in different $E$. coli pathotypes, shiga-toxin genes as well as genes encoding other virulence factors are located on dif- ferent prophages [55]. Diversification of prophages integrated in the chromosome of bacteria also appears to occur rapidly and commonly and contributes to bacterial genome evolution. For example, in enterohemorrhagic $E$. coli considerable diversification of prophages carrying virulence determinants has been observed, likely indicating independent infections of host bacteria by different bacteriophages carrying these virulence determinants [55]. Similarly, considerable diversity has been observed in the genome of the Vibrio CTX prophage (e.g., [56]). The importance of bacteriophages and lysogenic prophages in the evolution of gram-positive pathogens has also been documented (e.g., [57]). For example, the rapid emergence of serotype M3 group A Streptococcus (GAS) has been associated with the acquisition of a prophage that contained a unique combination of virulence genes, which was probably generated through several recombination events [58]. Moreover, most of the genetic diversity among GAS strains seems to be phage-related $[59,60]$. Prophages and diversification of prophage-associated genes thus appears to play an important role in the evolution of various bacterial species.

In addition to the diversification in the comK prophage, we also found that the four isolates differed in their plasmid content; a plasmid sequence was only found in the 2000 human isolate, as well as in nine additional human isolates linked to this outbreak. While our findings suggest that plasmid loss or acquisition events occurred, it can not be determined whether these changes occurred during L. monocytogenes survival in the processing plant, during passage of isolates, or during human infection. Rapid diversification of L. monocytogenes due to plasmid loss or acquisition has previously been reported and isolates from the same outbreak have been shown to differ in their plasmid profiles [21]. However, it is important to note that the media commonly used to isolate L. monocytogenes (particularly media used for isolation from food samples) contain acriflavine, a plasmid curing agent $[61,62]$. Therefore, it is possible that the isolates for which no plasmid sequence was obtained lost this plasmid during isolation or during laboratory passage.

\section{Genome sequence data support that a human listeriosis outbreak in $\mathbf{2 0 0 0}$ was caused by a L. monocytogenes strain that persisted in a food processing plant}

Our data showed that the human and food isolates from a sporadic case in 1988 and the human and food isolates from an outbreak in 2000, which were linked to the same food processing facility, had genome sequences that showed no major inversions, deletions and insertions, although minor changes like these cannot be ruled out since the genome sequences have not been fully finished and assembled. While the four isolates showed a total of 12 confirmed SNPs, all 11 SNPs that occurred in the 
genome backbone represented singletons, i.e., they were found in only one of the four isolates. The only mutations that differentiated the 1988 isolates from the 2000 isolates were (i) one single SNP in the tRNA-Thr-4-prophage and (ii) a large number of SNPs and deletions in the comK prophage, which most likely represent multiple recombination events. This high level of overall genome conservation between the human and food isolates from the 1988 listeriosis case and the 2000 outbreak strongly supports that these two incidences were caused by the same $L$. monocytogenes strain, which is likely to have persisted over at least 12 years in the processing plant that produced the food linked to both the 1988 case and the 2000 outbreak. Persistence is also supported by the observation that the PFGE type represented by the persistent strain seems rare (it was only found once among 495 food isolates characterized by PFGE [22]). Re-introduction from the immediate environment surrounding the plant is a possible, but unlikely, alternative to persistence of the specific strain in the processing plant, particularly as ready-to-eat meat processing plants will have controls in place to minimize introduction of microorganisms. Persistence in turkey flocks providing raw materials for this plant is even less likely as the heat treatment used for production of frankfurters and deli meats inactivates L. monocytogenes [63]. Similarly, re-introduction through a persistently infected worker is highly unlikely as people rarely shed $L$. monocytogenes $[64,65]$. Importantly, even in the unlikely scenario that the unique strain linked to listeriosis cases in 1998 and 2000 was reintroduced, rather than having persisted in the plant, the isolates characterized here would still represent a set of closely related isolates with a parentdescendant relationship, which have multiplied in a noncontrolled environment over about 12 years. Thus, the alternative scenarios outlined above do not affect the main conclusions of our study, including that phage mediated mechanisms are critical for short term diversification of L. monocytogenes.

Overall, our data demonstrate the utility of using full genome sequencing for follow-up investigations to epidemiological and source tracking studies. In particular, full genome sequencing clearly allowed for differentiation of the L. monocytogenes isolates from the 1988 case and the isolates associated with the 2000 outbreak, even though these isolates were previously found to be identical by other subtyping methods, including PFGE [26]. Genome sequencing not only represents the most sensitive subtyping approach conceivable, but also provides for specific identification of differences between isolates, which can be used to assess whether differences between two isolates are likely to have occurred within a short time frame or not. This assessment is critical for source tracking as genomic diversification that can lead to different genomic restriction profiles can clearly occur over short time peri- ods (e.g., through diversification of prophages, loss of plasmids). Rapid diversification in certain hot spots (e.g., prophages) represents a challenge as the current gold standard method for bacterial subtyping is a genomic restriction profiling approach (i.e., PFGE [66]), which means that closely related isolates may have different PFGE types (as seen in some outbreaks (e.g., [21,67]). Importantly though, the standard restriction enzymes used for L. monocytogenes PFGE analyses (i.e., ApaI and AscI [68]) only interrogate $<500 \mathrm{nt}$ for SNPs; based on the genome sequence for F6854, there are 39 restriction sites for ApaI, which recognizes a 6 bp motif (yielding $234 \mathrm{bp}$ of DNA interrogated by this enzyme), and 15 restriction sites for AscI, which recognizes a 8 bp motif (yielding 120 bp of DNA interrogated by this enzyme). Thus, genetically distinct isolates may share the same PFGE pattern. For example, Nightingale et al. [69] found that L. monocytogenes isolates with the same PFGE pattern may differ by presence/absence of premature stop codons in a number of genes, including the virulence gene inlB. In contrast to PFGE, our sequence analyses used $>2.9 \mathrm{Mb}$ of aligned sequences for subtype discrimination, thus providing for vastly improved detection of substitutions. While we cannot exclude that the isolates characterized show differences in their genomes in addition to those reported here (as the genomes have not been closed and include gaps), this approach clearly provides for a comprehensive sampling of the genomic diversity in the characterized isolates. Future use of full genome sequencing for epidemiological investigations of bacterial infectious disease outbreaks thus seems feasible assuming anticipated continued decreases in the cost of DNA sequencing [70] and availability of computational tools that allow for rapid and reliable genome assembly and comparisons.

\section{Isolate specific SNP patterns in the genomic backbone may occur during environmental growth, isolation or subculture}

Analysis of the single nucleotide polymorphism in the genome backbone of the isolates from both the 1988 listeriosis case and the 2000 listeriosis outbreak also provided us with the ability to probe the evolution of $L$. monocytogenes isolates during environmental persistence and during human infection. Based on our data, we hypothesize that the ancestor of F6854 and F6900 (1988 isolates) contaminated the plant in or before 1988. The single SNP differentiating the 1988 human isolate from the 1988 food isolate is consistent with a very close ancestral relationship between these two isolates; the unique SNP in the human isolate could have occurred in the ancestor of the human isolate (F6900) during multiplication in either the plant, the contaminated food, or the infected human or during isolation and propagation of the isolate. The ancestor of F6854 remained in the plant and persisted until 2000. Between 1988 and 2000, the 
comK prophage of that strain was replaced (through one or several recombination events) by the prophage found in the 2000 isolates. Moreover, one mutation that differentiates the 1988 isolates from the 2000 isolates occurred in the tRNA prophage (possibly through a substitution or due to a recombination event). After the comK prophage replacement and the tRNA mutation, one mutation in J0161 (the 2000 human isolate) and eight mutations in J2818 (the 2000 food isolate) occurred and differentiated these two isolates from each other and from the 1988 isolates. The substitution that is unique to the 2000 human isolate must have occurred during growth prior to infection and isolation as it was found in the sequenced human isolate (J0161) as well as in an additional 9 human isolates (see Figure 3). On the other hand, the substitutions in the 2000 food isolate could have occurred during multiplication in the plant, the contaminated food, or during isolation and laboratory propagation. The observation that the 2000 food isolate carries eight unique SNPs, which clearly separated this isolate from the other three isolates, while carrying a comK prophage region identical to the 2000 human isolate, suggests that these mutations occurred after the two 2000 isolates diverged from the 1988 strain. The possibility that these SNPs arose during laboratory passages is supported by our observation that two subcultures of the 2000 human isolates differed by one SNP as well as observations that two subcultures of Bacillus anthracis strain Porton differed by a number of SNPs [71].

\section{Conclusion}

Analyses of full genome data of four L. monocytogenes isolates associated with a sporadic human listeriosis case (in 1988) and a subsequent outbreak (in 2000), both linked to the same food processing facility, not only demonstrated the utility of full genome sequencing for detailed follow-up studies that can provide an improved understanding of infectious disease transmission, but also represent one of the few datasets that provide insights at the full genome level into evolutionary patterns of bacteria in non-controlled environments. The limited number of mutations observed in the genome backbone are consistent with mutation rates in bacteria previously calculated using data from both experimental (e.g., [2,3]) and natural populations [38]. Rather than single base-pair mutations or rearrangements in the genomic backbone, diversification in prophage sequences, and possibly plasmid loss and acquisition (as also supported by data from others [21]), seem to represent the major drivers of diversification in L. monocytogenes in non-controlled environments. Interestingly, in L. monocytogenes, diversification by these mechanisms seems to not target virulence genes as neither plasmid nor phage-based $L$. monocytogenes virulence genes have been identified so far. The clearly observed pattern of considerable phage-mediated diversification in highly related L. monocytogenes isolates with nearly identical genome backbone sequences also demonstrates that the absence of any possibility for phage-mediated diversification during in vitro evolution studies of bacteria represents a major constraint associated with these studies. This report is one of the first studies on the short-term genome evolution of bacteria in a non-controlled environment, thus providing important information that may help in interpretation of data from laboratory evolution experiments. Despite the fact that studies on naturally evolving populations in non-controlled environments will necessarily include a number of drawbacks (e.g., difficulty in identifying parent-descendant pairs with a specific number of separating generations), these studies are a critical complement to laboratory-based studies and are needed to improve our understanding of the evolution of bacteria in natural environments.

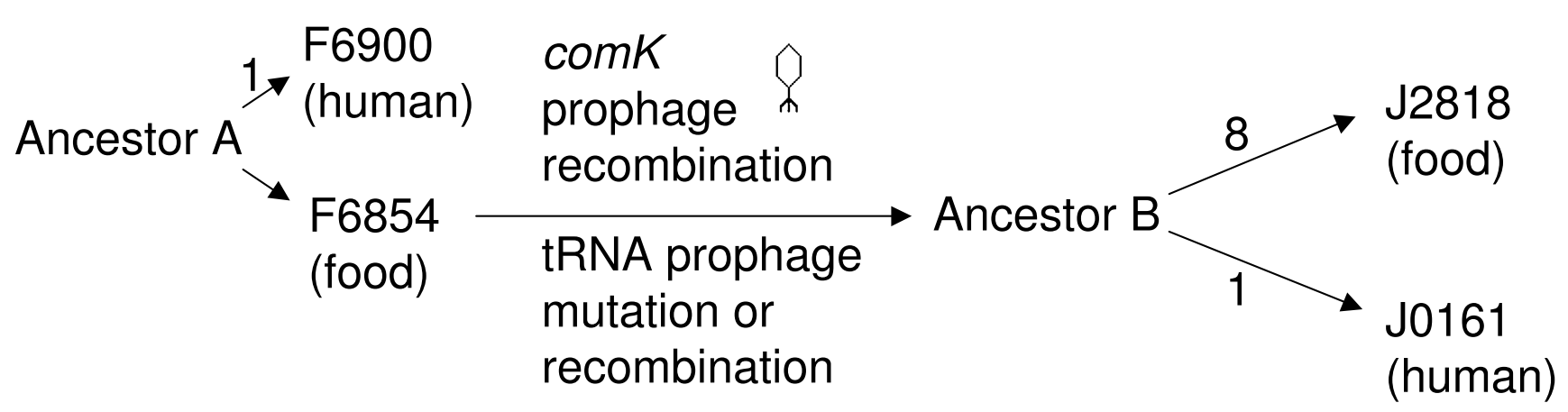

\section{Figure 3}

Schematic of the putative evolutionary history of the L. monocytogenes strain in the food facility between 1988 and 2000. Numbers on the arrows represent new mutations. Ancestor $A$ is the ancestor of F6854 and F6900 (the food and human isolate, respectively, from the sporadic case in 1988) and Ancestor B is the ancestor of J0I6I and J28I8 (the food and human isolate, respectively, from the outbreak in 2000). 


\section{Methods}

\section{L. monocytogenes isolates}

The primary isolates characterized here were a human and a food isolate from a 1988 sporadic listeriosis case in the US [24] (isolates F6900 and F6854; Table 1) as well as a human and a food isolate from a 2000 listeriosis outbreak in the US [25] (isolates J0161 and J2818; Table 1). Isolates F6900, J0161 and J2818 used for preparation of DNA for genome sequencing were directly sent from the US Centers for Disease Control and Prevention (CDC) to Anza Therapeutics, Inc. for genomic DNA isolation. Subcultures used for re-sequencing (to confirm selected polymorphisms) and for tissue culture were independently provided to Cornell from the CDC. At the CDC, isolates were stored at $-70^{\circ} \mathrm{C}$ in sheep's blood (isolate F6900) or in trypticase soy broth with $20 \%$ glycerol (J0161 and J2818). At Cornell, all isolates were stored at $-80^{\circ} \mathrm{C}$ in brain heart infusion broth with $15 \%$ glycerol.

F6854, the food isolate from the 1988 listeriosis case (Table 1) was isolated from direct plating of the food sample on lithium chloride - phenylethanol- moxalactam (LPM) agar. While the specific details of the isolation procedures for J2818, the 2000 food isolate, were not available, standard procedures for isolation of L. monocytogenes from meat products in 2000 would involve primary enrichment in University of Vermont (UVM) broth and secondary enrichment in Fraser Broth (FB) or Buffered Listeria Enrichment Broth (BLEB), followed by plating on Modified Oxford (MOX)(MLG 8.06 and MLG 8A.03, the protocols are available at [72]); all of these enrichment media as well as MOX include acriflavine, a potential DNA modifying and plasmid curing agent $[61,62]$.

Standard protocols for the isolation of L. monocytogenes from human patients involve collection of blood or cerebrospinal fluid (CSF) with a syringe or directly into blood culture bottles. The blood culture enrichment is sub-cultured onto appropriate plating media (e.g. trypticase soy agar supplemented with 5\% defibrinated sheep's blood) at regular intervals. While human isolate F6900 (Table 1) was isolated via blood culture by this protocol (Swaminathan and Graves, unpublished), the procedure used for isolation of human isolate J0161 is not available. Unfortunately, no specific data on the number of passages for each isolate are available.

\section{Genome sequencing}

High molecular weight genomic DNA was isolated from overnight cultures grown in buffered yeast media. Bacteria were lysed using lysin from phage 10403 [46] that had been cloned and purified as described [73]. Genomic DNA was isolated using QIAGEN genomic-tip 100/G columns per manufacturer's recommendations.
Genome sequences for isolates J0161 (human isolate, 2000 listeriosis outbreak) [25,26], J2818 (food isolate, 2000 listeriosis outbreak) [25,26], F6900 (human isolate, 1998 listeriosis case) [24], and isolate FSL J1-194 (unrelated human isolate from a sporadic case [42] were determined at the Broad Institute using the 454 technology [29]. 454 data were assembled using the 454 Newbler assembler, version v1.0.52.60 [74]. Assembly quality metrics for each of the four genome assemblies are described in Table 2. In all cases, the assembly covers $\geq 93 \%$ of the finished reference and the N50 contig size is at least 148 $\mathrm{kb}$. N50 contig size is a length-weighted median representing the size contig in which the typical base is found.

Whole genome shotgun end sequencing of plasmids with 4 to $10 \mathrm{~kb}$ inserts and fosmids with $40 \mathrm{~kb}$ inserts was performed by ABI BigDye chemistry and detected on ABI 3730 machines as described previously [75].

\section{Genome sequences used for analyses}

The draft genomes of J0161 (version 1), J2818 (version 2), F6900 (version 2) (NCBI accession nos. AARW00000000.1, AARX00000000.1, and AARU00000000.1), sequenced as described above, as well as the unfinished sequence of F6854 (AADQ00000000.1), obtained from the Comprehensive Microbial Resource [76] were used for all analyses. In addition to the chromosome sequences for these four isolates; we also analyzed the plasmid sequence found in the 2000 human isolate (J0161). The genome sequence of F6854 represented a pseudomolecule in which gaps between the contigs were closed with random sequences using the fully sequenced genome of EGD-e as a reference; all details on the construction of this pseudomolecule were described by [28]. The synthetic sequences introduced to close gaps were deleted from F6854 after the initial genome alignment using TBA (as detailed below) and prior to further manipulations and analyses.

The genome sequence for the lineage I strain FSL J1-194 (version 2) (NCBI accession no. AARJ00000000.1), also determined at the Broad Institute, was used for recombination analyses; like the other genomes used here, the genome of FSL J1-194 has not been fully sequenced and closed.

\section{Genome alignments}

The package TBA (Threaded-Blockset Aligner) [30] was used to align the five genomes (i.e., the 1998 and 2000 human and food isolates as well as FSL J1-194) with the package's default settings. TBA runs a series of blastz alignments (i.e., pairwise sequence alignment) between the genome sequences for each isolate. These alignments are subsequently used to build multiple alignment blocks; each block contains the sequences for the isolates 
included in a pairwise alignment that had been created in the first step. If, for example, J0161 did not have a specific fragment "A" or if the fragment had not been sequenced in this isolate, J0161 did not appear in the block for fragment "A". Because the genome sequence of four of the five isolates is represented in multiple contigs (Table 1), several blocks were created; each block could not contain more than one contig from a given isolate. The blocks were filtered to keep only those blocks that contained sequences from all isolates analyzed. The F6854 sequence was used as a reference to order blocks such that the first block started at the start of the F6854 sequence and the last block ended at the end of the F6854 sequence. After completion of the alignment, 62 ambiguous sites in the F6854 genome sequence (e.g., $\mathrm{R}, \mathrm{S}, \mathrm{W}$, etc.) were manually changed to the consensus sequence of the other isolates at the same position (at all of these sites isolates J0161, J2818, and F6900 had the same nt; thus, these manipulations would not underestimate the number of true differences between the 1988 and 2000 isolates or between the food and human isolates). The alignment blocks were subsequently edited using custom perl scripts (developed by the authors) and BioEdit version 7.0.5.2 [77] to create one multiple alignment of the sequences in which the blocks were ordered according to the F6854 chromosomal sequence. This alignment was further refined using the program MUSCLE version 3.6 [31] using a gap open penalty of -75.0 , a gap extension penalty of 1.0, and the default settings for all other parameters.

\section{Genome alignment analyses}

The final alignment was separated into three sub-alignments, including alignments for (i) the prophage inserted into $c o m K$; (ii) the prophage inserted into tRNA-Thr-4; and (iii) the genome backbone sequence without the two prophage sequences. These alignments were initially analyzed using DnaSP version 4.0 [78] to identify polymorphic sites in all three alignments. A perl script was developed to identify positions with gaps in the alignment and to identify which sequences had the gaps.

The number of synonymous sites in the genome of F6854 (i.e., $5.65 \times 10^{5}$ synonymous sites) was calculated as previously described [3] using all annotated protein coding sequences with the exception of the ORFs present within the two prophages.

\section{Analysis of comK prophage sequences}

The coding sequences for all genes annotated in the $\operatorname{comK}$ prophage in the 2000 isolates (J2818 and J0161) were used as queries in blastn searches against (i) the genomic sequence of F6854 (1988 food isolate); (ii) the Listeria database at the Broad Institute website [42]; and (iii) GenBank [41]. For those comK prophage genes present in the 2000 isolates that did not have homologous sequences in the 1988 human and food isolates (F6854 and F6900) in the initial blastn search, the absence of a homologue was confirmed by inspection of the corresponding region of the prophage in F6854 (1988 food isolate).

\section{Recombination analyses}

Recombination analyses were performed using Sawyer's test implemented in GENECONV [79]; GENECONV default settings were used for the analyses with the exception that sites with gaps were not considered and mismatches were allowed within the recombinant fragment (gscale $=3$ ).

\section{Confirmation of polymorphic sites}

All 43 polymorphic sites in the backbone alignment and the single polymorphic site in the tRNA Thr- 4 prophage were initially checked by comparison with pre-existing Sanger trace files available from NCBI for isolates J0161, J2818 and F6854. If Sanger trace files were not available, polymorphisms were confirmed by re-sequencing; for this purpose, PCR primers were designed, using the F6854 genome as reference, to amplify the regions flanking the polymorphisms (Additional file 3). A total of 33 pairs of primers were designed since in a few cases multiple polymorphic sites could be amplified in a single fragment. PCR products were purified using Exonuclease I (0.5 U/ $\mu \mathrm{l})$ and Shrimp alkaline phosphatase $(0.05 \mathrm{U} / \mu \mathrm{l})$ (USB, NEB) and sequenced, using standard Sanger fluorescent sequencing methods, at the Core Laboratories Center at Cornell University, USA. Among the PCRs performed for sequencing, five amplified more than one fragment (three amplified two fragments and two amplified three fragments), suggesting that those regions represented repetitive regions in the chromosome. Blastn searches of the target sequences that were used to design these five primer sets against the genomes of F6854 and EGD-e confirmed that the fragments amplified by these primers represented almost identical repetitive sequences and DNA sequencing showed that the polymorphic sites initially identified in these regions were due to misalignments of repetitive sequences. Overall, 11 polymorphisms were confirmed by re-sequencing; importantly, the one SNP in the genome backbone initially identified as differentiating the two 1988 and the two 2000 isolates was not confirmed. Interestingly, one polymorphism in the 2000 food isolate (J0161; SNP \#3; Table 3) was not confirmed by resequencing, but was confirmed in the trace files available in NCBI, indicating that this polymorphism most likely occurred during laboratory passage of the J0161 subculture sequenced at the Broad Institute (as the sequence at this site in the J0161 subculture at Cornell matched the other 2000 isolate and the two 1988 isolates); we considered this polymorphism as a confirmed polymorphism as it was present in the actual isolate sequenced. In summary, thus, among all 44 polymorphisms identified ini- 
tially, 12 were confirmed. Among the 32 polymorphism not confirmed, eight represented sequencing errors in F6854 (which was sequenced with the Sanger method) and one represented a sequencing error in J2818; 12 of the polymorphisms that were not confirmed represent problems in the number of bases within homopolymeric tracts and misplacement of the gap in the alignment, and 11 represented misalignments of repetitive regions (Additional file 4).

\section{Confirmation of selected indels}

We also chose genome alignment gaps (representing possible indels) that (i) differentiated the two 1988 isolates from the two 2000 isolates (26 gaps) or (ii) differentiated the two human isolates from the two food isolates (34 gaps) for verification. Gaps were initially verified using Sanger trace files available for isolates J0161, J2818 and F6854 and sequencing by synthesis technologies data files. For a total of six gaps that could not be verified either due to ambiguous sequence data or lack of Sanger sequencing data, verification was performed using resequencing; PCR primer design and sequencing were performed as described above. One additional gap was present in a sequence representing a multicopy gene (i.e., a 235 rRNA sequence); no validation of this gap was attempted.

Verification of the 59 gaps by comparison with pre-existing trace files available in NCBI or by re-sequencing showed that all of these gaps represented alignment artifacts or artifacts due to the sequencing by synthesis technology. Thus, none of the short indels that were initially identified as differentiating the two 1998 from the two 2000 isolates or the two human from the two food isolates could be confirmed and these initially identified indels appear to represent sequencing errors, consistent with previous reports that the sequencing by synthesis strategy often incorrectly characterizes homopolymeric tracts [3].

\section{Validation of selected polymorphisms and plasmid presence using additional human isolates linked to the 2000 listeriosis outbreak}

In order to identify additional human isolates linked to the 2000 outbreak, the Pathogen Tracker [80] database was used to identify human isolates that shared the same ribotype as the outbreak strain (DUP-1053A) and were isolated during the time frame of the outbreak (May to November of 2000) in some of the states (New York, Michigan and Ohio) that were included in the outbreak. Selected isolates identified through this approach were tested for rhamnose fermentation as well as by PFGE to identify specific isolates that matched the outbreak strain. Rhamnose fermentation was tested as previously described [81] with the exception that only one tube with- out a mineral oil overlay was used. PFGE with the restriction enzymes ApaI and AscI was performed using the US CDC standard PulseNet protocol [68]. Nine isolates matching the rhamnose fermentation characteristics and PFGE profile of the 1988 and 2000 isolates were selected to validate the polymorphisms described in Table 3 using PCR amplification and subsequent sequencing (see Additional file 3 for primers) of the regions containing these polymorphisms. All 9 of these isolates were also screened for the presence of two plasmid-specific sequences using PCR (see Additional file 3 for primers).

Unfortunately neither additional food nor additional human isolates linked to the 1988 case were available for analyses. Furthermore, no additional food or plant environmental isolates from 2000 or the period between 1998 and 2000 were available for analyses.

\section{Intracellular growth assay in activated 1774 macrophage- like cells}

L. monocytogenes strains were grown in $\mathrm{BHI}$ at $37^{\circ} \mathrm{C}$ with shaking at 220 RPM. Log phase $\left(\mathrm{OD}_{600}=0.4\right)$ L. monocytogenes strains in $\mathrm{BHI}$ were diluted 1:100 and grown at $37^{\circ} \mathrm{C}$ to early stationary phase (defined as $3 \mathrm{~h}$ after the $\mathrm{OD}_{600}$ reached 1.0). Aliquots of the stationary phase cultures were flash frozen in liquid nitrogen and cultures were enumerated after thawing. The murine macrophage cell line J774A.1 (ATCC TIB-67) was maintained using Dulbecco's minimal essential medium (DMEM) with Earle's salts and 1\% sodium pyruvate (Gibco; Gaithersburg, MD) containing 10\% fetal bovine serum (Gibco), $1.5 \mathrm{~g} / \mathrm{L}$ sodium bicarbonate (Gibco), and $100 \mu \mathrm{g} / \mathrm{ml}$ each penicillin G and streptomycin (J774 medium).

Intracellular growth assays were performed as described by Conte et al., [82] with minor modifications. Briefly, 48 $\mathrm{h}$ prior to the assay, J774 cells were seeded into 24 well plates (Corning) at a density of $2 \times 10^{5}$ cells/well in J774 medium without antibiotics. Twenty-four hours after seeding, the medium was replaced with J774 medium supplemented with $0.1 \mu \mathrm{g} / \mathrm{ml}$ E. coli O55:B5 LPS (Sigma). Thirty minutes prior to infection, the medium was replaced with fresh J774 medium without antibiotics. For infection, approximately $1 \times 10^{6} \mathrm{CFU}$ L. monocytogenes were added to each well, resulting in an MOI of approximately 1 . At 30 minutes post infection, the monolayers were washed once with PBS to remove any unassociated $L$. monocytogenes, and the medium was replaced with J774 media containing $50 \mu \mathrm{g} / \mathrm{ml}$ gentamycin to kill any extracellular L. monocytogenes. Infected J774 cells in different wells were washed 3 times with PBS and lysed with icecold distilled water after at $1,5,7$, or $9 \mathrm{~h}$ post infection. Intracellular L. monocytogenes were enumerated by plating the appropriate dilutions of the J774 lysate on BHI. 
Intracellular growth assays were initially performed separately with the two isolates to be tested (i.e., J0161 and J2818), but were also performed in a competition experiment format [36,37], where activated J774 cells were infected with both L. monocytogenes isolates (mixed at a 1:1 ratio). To assess the frequency of each strain after intracellular growth in the competition experiment, ten colonies recovered after $9 \mathrm{~h}$ of intracellular growth were selected from each of the three replicates for PCR amplification and sequencing of the region containing SNP 10 (Table 3) using primers RHO105-2327842F and RHO106-2327842R (Additional file 3).

\section{Authors' contributions}

RHO perceived the study, performed genome alignments and genome alignment analyses, and re-sequencing of selected polymorphic sites; he drafted the manuscript. MLB formed and led the genome sequencing collaboration, participated in design and coordination of the study and helped draft the manuscript. SKY performed analysis and assembly of the 454 sequence data to create the genome sequences. $\mathrm{CN}$ led the 454 sequencing effort. JEG participated in the design and coordination of the study. BWB participated in the design and coordination of the study. PL developed and utilized the methods to rapidly isolate high quality genomic DNA from $L$. monocytogenes isolates and helped draft the manuscript. QS developed perl scripts required for analyses. RAI performed tissue culture experiments. LMG curated and provided bacterial isolates and researched isolate history. BS participated in the design and coordination of the study and helped draft the manuscript. MW participated in the design and coordination of the study and helped draft the manuscript. All authors read and approved the final manuscript.

\section{Additional material}

\section{Additional file 1}

Intracellular growth of isolates J2818 and J0161 in activated J774 macrophage cells. Graph of intracellular growth in activated macrophages of isolates J2818 and J0161.

Click here for file

[http://www.biomedcentral.com/content/supplementary/1471-

2164-9-539-S1.doc]

\section{Additional file 2}

Comparison of comK prophage genes present in the human clinical and food isolates associated with the 1988 sporadic listeriosis case and the 2000 listeriosis outbreak. This table provides a gene-by-gene analysis of the comK prophage in strain F6854 (representing the 1988 isolates), $J 2818$ (representing the 2000 isolates), and other L. monocytogenes strains.

Click here for file

[http://www.biomedcentral.com/content/supplementary/14712164-9-539-S2.doc]

\section{Additional file 3}

Primers used for validation of polymorphisms. List of primers used for validation of polymorphisms identified during genome analysis.

Click here for file

[http://www.biomedcentral.com/content/supplementary/1471-

2164-9-539-S3.doc]

\section{Additional file 4}

Validation of the 43 polymorphic sites in the backbone alignment and the single polymorphic site in the tRNA prophage that were initially identified in the genome comparisons. This table describes the 44 polymorphisms identified in the genome analysis, including whether a given polymorphism was confirmed by PCR amplification and subsequent sequencing of the PCR product.

Click here for file

[http://www.biomedcentral.com/content/supplementary/14712164-9-539-S4.doc]

\section{Acknowledgements}

This work was partially supported by USDA Special Research Grants 200534459-15625 and 34459-16952-06 (to MW). We thank USDA FSIS and Kitty Pupedis for providing isolate 12818 and for providing information on the history of this isolate. We also thank Yesim Soyer for help with PFGE analyses and Barbara Bowen for help with the rhamnose tests.

\section{References}

I. Nakatsu CH, Korona R, Lenski RE, de Bruijn FJ, Marsh TL, Forney LJ: Parallel and divergent genotypic evolution in experimental populations of Ralstonia sp. J Bacteriol 1998, I 80:4325-433|.

2. Lenski RE, Winkworth CL, Riley MA: Rates of DNA sequence evolution in experimental populations of Escherichia coli during 20,000 generations. J Mol Evol 2003, 56(4):498-508.

3. Velicer G], Raddatz G, Keller H, Deiss S, Lanz C, Dinkelacker I, Schuster SC: Comprehensive mutation identification in an evolved bacterial cooperator and its cheating ancestor. Proc Natl Acad Sci USA 2006, 103:8107-8II2.

4. Bergthorsson $\mathrm{U}$, Ochman $\mathrm{H}$ : Chromosomal changes during experimental evolution in laboratory populations of Escherichia coli. J Bacteriol 1999, I81:1360-1363.

5. Woods R, Schneider D, Winkworth CL, Riley MA, Lenski RE: Tests of parallel molecular evolution in a long-term experiment with Escherichia coli. Proc Natl Acad Sci USA 2006, 103:9107-9II 2.

6. Weis J, Seeliger HP: Incidence of Listeria monocytogenes in nature. Appl Microbiol 1975, 30:29-32.

7. Yoshida T, Sugimoto T, Sato M, Hirai K: Incidence of Listeria monocytogenes in wild animals in Japan. J Vet Med Sci 2000, 62:673-675.

8. Mead PS, Slutsker L, Dietz V, McCaig LF, Bresee JS, Shapiro C, Griffin PM, Tauxe RV: Food-related illness and death in the United States. Emerg Infect Dis 1999, 5:607-625.

9. Roberts AJ, Wiedmann M: Pathogen, host and environmental factors contributing to the pathogenesis of listeriosis. Cell Mol Life Sci 2003, 60:904-918.

10. Gray ML, Killinger AH: Listeria monocytogenes and listeric infections. Bacteriol Rev 1966, 30:309-382.

II. Walker SJ, Archer P, Banks JG: Growth of Listeria monocytogenes at refrigeration temperatures. J Appl Bacteriol 1990, 68:157-162.

12. Petran RL, Zottola EA: A study of factors affecting growth and recovery of Listeria monocytogenes Scott A. J Food Science 1989, 54:458-460.

13. Phan-Thanh L: Physiological and biochemical aspects of the acid survival of Listeria monocytogenes. J Gen Appl Microbiol I 998, 44:|83-19|.

14. Kathariou S: Listeria monocytogenes virulence and pathogenicity, a food safety perspective. J Food Prot 2002, 65:181 I-1829. 
15. Lappi VR, Thimothe J, Walker J, Bell J, Gall K, Moody MW, Wiedmann $M$ : Impact of intervention strategies on Listeria contamination patterns in crawfish processing plants: a longitudinal study. I Food Prot 2004, 67: I I63- I I 69.

16. Thimothe J, Nightingale KK, Gall K, Scott VN, Wiedmann M: Tracking of Listeria monocytogenes in smoked fish processing plants. J Food Prot 2004, 67:328-34I.

17. Hu Y, Gall K, Ho A, Ivanek R, Grohn YT, Wiedmann M: Daily variability of Listeria contamination patterns in a cold-smoked salmon processing operation. J Food Prot 2006, 69:2 I 23-2 I 33

18. Kabuki DY, Kuaye AY, Wiedmann M, Boor KJ: Molecular Subtyping and Tracking of Listeria monocytogenes in Latin-Style Fresh-Cheese Processing Plants. J Dairy Sci 2004, 87:2803-28I 2.

19. Klaeboe H, Rosef O, Fortes E, Wiedmann M: Ribotype diversity of Listeria monocytogenes isolates from two salmon processing plants in Norway. Int J Environ Health Res 2006, I 6:375-383.

20. Chambel L, Sol M, Fernandes I, Barbosa M, Zilhao I, Barata B, Jordan S, Perni S, Shama G, Adriao A, Faleiro L, Requena T, Pelaez C, Andrew PW, Tenreiro R: Occurrence and persistence of Listeria spp. in the environment of ewe and cow's milk cheese dairies in Portugal unveiled by an integrated analysis of identification, typing and spatial-temporal mapping along production cycle. Int J Food Microbiol 2007, I | 6:52-63.

21. Kathariou S, Graves L, Buchrieser C, Glaser P, Siletzky RM, Swaminathan B: Involvement of closely related strains of a new clonal group of Listeria monocytogenes in the 1998-99 and 2002 multistate outbreaks of foodborne listeriosis in the United States. Foodborne Pathog Dis 2006, 3:292-302.

22. Fugett EB, Schoonmaker-Bopp D, Dumas NB, Corby J, Wiedmann M: Pulsed-field gel electrophoresis (PFGE) analysis of temporally matched Listeria monocytogenes isolates from human clinical cases, foods, ruminant farms, and urban and natural environments reveals source-associated as well as widely distributed PFGE types. I Clin Microbiol 2007, 45:865-873.

23. Shen Y, Liu Y, Zhang Y, Cripe J, Conway W, Meng J, Hall G, Bhagwat $\mathrm{AA}$ : Isolation and characterization of Listeria monocytogenes isolates from ready-to-eat foods in Florida. Appl Environ Microbiol 2006, 72:5073-5076

24. Centers for Disease Control and Prevention: Epidemiological notes and reports listeriosis associated with consumption of Turkey Franks. MMWR Morb Mortal Wkly Rep 1989, 38:267-268.

25. Stone SC, Shoenberger J: Update: Multistate outbreak of listeriosis - United States, 2000. Ann Emerg Med 200I, 38:339-34I

26. Olsen SJ, Patrick M, Hunter SB, Reddy V, Kornstein L, MacKenzie WR, Lane K, Bidol S, Stoltman GA, Frye DM, Lee I, Hurd S, Jones TF, LaPorte TN, Dewitt W, Graves L, Wiedmann M, Schoonmaker-Bopp DJ, Huang AJ, Vincent C, Bugenhagen A, Corby J, Carloni ER, Holcomb ME, Woron RF, Zansky SM, Dowdle G, Smith F, Ahrabi-Fard S, Ong AR, Tucker N, Hynes NA, Mead P: Multistate outbreak of Listeria monocytogenes infection linked to delicatessen turkey meat. Clin Infect Dis 2005, 40:962-967.

27. Fugett E, Fortes E, Nnoka C, Wiedmann M: International Life Sciences Institute North America Listeria monocytogenes strain collection: development of standard Listeria monocytogenes strain sets for research and validation studies. J Food Prot 2006 , 69:2929-2938.

28. Nelson KE, Fouts DE, Mongodin EF, Ravel J, DeBoy RT, Kolonay JF, Rasko DA, Angiuoli SV, Gill SR, Paulsen IT, Peterson J, White O, Nelson WC, Nierman W, Beanan MJ, Brinkac LM, Daugherty SC, Dodson RJ, Durkin AS, Madupu R, Haft DH, Selengut J, Van Aken S, Khouri H, Fedorova N, Forberger $H$, Tran B, Kathariou S, Wonderling LD, Uhlich GA, Bayles DO, Luchansky JB, Fraser CM: Whole genome comparisons of serotype $4 b$ and $I / 2 a$ strains of the foodborne pathogen Listeria monocytogenes reveal new insights into the core genome components of this species. Nucleic Acids Res 2004, 32:2386-2395.

29. Margulies M, Egholm M, Altman WE, Attiya S, Bader IS, Bemben LA, Berka J, Braverman MS, Chen YJ, Chen Z, Dewell SB, Du L, Fierro JM, Gomes XV, Godwin BC, He W, Helgesen S, Ho CH, Irzyk GP, Jando SC, Alenquer ML, Jarvie TP, Jirage KB, Kim JB, Knight JR, Lanza JR, Leamon JH, Lefkowitz SM, Lei M, Li J, Lohman KL, Lu H, Makhijani VB, McDade KE, McKenna MP, Myers EW, Nickerson E, Nobile JR, Plant R, Puc BP, Ronan MT, Roth GT, Sarkis GJ, Simons JF, Simpson JW Srinivasan M, Tartaro KR, Tomasz A, Vogt KA, Volkmer GA, Wang SH, Wang Y, Weiner MP, Yu P, Begley RF, Rothberg JM: Genome sequencing in microfabricated high-density picolitre reactors. Nature 2005, 437:376-380.

30. Blanchette M, Kent WJ, Riemer C, Elnitski L, Smit AF, Roskin KM, Baertsch R, Rosenbloom K, Clawson H, Green ED, Haussler D, Miller $W$ : Aligning multiple genomic sequences with the threaded blockset aligner. Genome Res 2004, I 4:708-7I5.

31. Edgar RC: MUSCLE: a multiple sequence alignment method with reduced time and space complexity. BMC Bioinformatics 2004, 5: II3.

32. Alonso JC, Tailor RH, Luder G: Characterization of recombination-deficient mutants of Bacillus subtilis. J Bacteriol I988, 170:300|-3007.

33. Kooistra J, Vosman B, Venema G: Cloning and characterization of a Bacillus subtilis transcription unit involved in ATP. dependent DNase synthesis. J Bacteriol 1988, I 70:479|-4797.

34. Chedin F, Noirot P, Biaudet V, Ehrlich SD: A five-nucleotide sequence protects DNA from exonucleolytic degradation by AddAB, the RecBCD analogue of Bacillus subtilis. Mol Microbiol 1998, 29:1369-1377.

35. Spek EJ, Wright TL, Stitt MS, Taghizadeh NR, Tannenbaum SR, Marinus MG, Engelward BP: Recombinational repair is critical for survival of Escherichia coli exposed to nitric oxide. J Bacteriol 2001, I83:13|-138.

36. Auerbuch V, Lenz LL, Portnoy DA: Development of a competitive index assay to evaluate the virulence of Listeria monocytogenesact $A$ mutants during primary and secondary infection of mice. Infect Immun 200I, 69:5953-5957.

37. Nilsson AI, Kugelberg E, Berg OG, Andersson DI: Experimental adaptation of Salmonella typhimurium to mice. Genetics 2004 | 68: I| 19-1|30.

38. Ochman H, Elwyn S, Moran NA: Calibrating bacterial evolution. Proc Natl Acad Sci USA 1999, 96: I 2638- I 2643.

39. Francois K, Devlieghere F, Standaert AR, Geeraerd AH, Van Impe JF, Debevere J: Effect of environmental parameters (temperature, $\mathrm{pH}$ and $\mathrm{a}(\mathrm{w})$ ) on the individual cell lag phase and generation time of Listeria monocytogenes. Int J Food Microbiol 2006 , 108:326-335.

40. Botzler RG, Cowan AB, Wetzler TF: Survival of Listeria monocytogenes in soil and water. J Wild Dis 1974, 10:204-212.

4I. GenBank [http://www.ncbi.nlm.nih.gov/Genbank]

42. Listeria monocytogenes database at Broad Institute [http:www.broad.mit.edu/annotation/genome/listeria group/Multi Home.html]

43. Glaser P, Frangeul L, Buchrieser C, Rusniok C, Amend A, Baquero F, Berche $\mathrm{P}$, Bloecker $\mathrm{H}$, Brandt $\mathrm{P}$, Chakraborty $\mathrm{T}$, Charbit A, Chetouani F, Couve E, de Daruvar A, Dehoux P, Domann E, Dominguez-Bernal G, Duchaud E, Durant L, Dussurget O, Entian KD, Fsihi H, Garcia-del Portillo F, Garrido P, Gautier L, Goebel W, Gomez-Lopez N, Hain T, Hauf J, Jackson D, Jones LM, Kaerst U, Kreft J, Kuhn M, Kunst F, Kurapkat G, Madueno E, Maitournam A, Vicente JM, Ng E, Nedjari H, Nordsiek G, Novella S, de Pablos B, Perez-Diaz JC, Purcell R, Remmel $B$, Rose M, Schlueter T, Simoes N, Tierrez A, Vazquez-Boland JA, Voss H, Wehland J, Cossart P: Comparative genomics of Listeria species. Science 200I, 294:849-852.

44. Loessner MJ, Inman RB, Lauer P, Calendar R: Complete nucleotide sequence, molecular analysis and genome structure of bacteriophage Al 8 of Listeria monocytogenes : implications for phage evolution. Mol Microbiol 2000, 35:324-340.

45. Brabban AD, Hite E, Callaway TR: Evolution of foodborne pathogens via temperate bacteriophage-mediated gene transfer. Foodborne Pathog Dis 2005, 2:287-303.

46. Hodgson DA: Generalized transduction of serotype I/2 and serotype $4 \mathrm{~b}$ strains of Listeria monocytogenes. Mol Microbiol 2000, 35:312-323.

47. Nightingale KK, Windham K, Wiedmann M: Evolution and molecular phylogeny of Listeria monocytogenes isolated from human and animal listeriosis cases and foods. J Bacteriol 2005, | 87:5537-555।.

48. Tsai YH, Orsi RH, Nightingale KK, Wiedmann M: Listeria monocytogenes internalins are highly diverse and evolved by recombination and positive selection. Infect Genet Evol 2006, 6:378-389.

49. Orsi RH, Ripoll DR, Yeung M, Nightingale KK, Wiedmann $M$ Recombination and positive selection contribute to evolution of Listeria monocytogenes inIA. Microbiology 2007, I53:2666-2678. 
50. Faruque SM, Islam MJ, Ahmad QS, Faruque AS, Sack DA, Nair GB, Mekalanos JJ: Self-limiting nature of seasonal cholera epidemics: Role of host-mediated amplification of phage. Proc Natl Acad Sci USA 2005, I 02:6 | | 9-6I 24

51. Faruque SM, Naser IB, Islam MJ, Faruque AS, Ghosh AN, Nair GB, Sack DA, Mekalanos J]: Seasonal epidemics of cholera inversely correlate with the prevalence of environmental cholera phages. Proc Natl Acad Sci USA 2005, 102: I702-I 707.

52. Blokesch M, Schoolnik GK: Serogroup conversion of Vibrio cholerae in aquatic reservoirs. PLoS Pathog 2007, 3:e81

53. Waldor MK, Mekalanos J): Lysogenic conversion by a filamentous phage encoding cholera toxin. Science 1996 272:1910-1914

54. Faruque SM, Asadulghani, Alim AR, Albert MJ, Islam KM, Mekalanos $\mathrm{J}$ : Induction of the lysogenic phage encoding cholera toxin in naturally occurring strains of toxigenic Vibrio cholerae $\mathrm{OI}$ and O139. Infect Immun 1998, 66:3752-3757.

55. Ogura Y, Ooka T, Asadulghani, Terajima J, Nougayrede JP, Kurokawa K, Tashiro K, Tobe T, Nakayama K, Kuhara S, Oswald E, Watanabe $\mathrm{H}$, Hayashi $\mathrm{T}$ : Extensive genomic diversity and selective conservation of virulence-determinants in enterohemorrhagic Escherichia coli strains of OI57 and non-OI57 serotypes. Genome Biol 2007, 8:RI38.

56. Li M, Kotetishvili M, Chen Y, Sozhamannan S: Comparative genomic analyses of the vibrio pathogenicity island and cholera toxin prophage regions in nonepidemic serogroup strains of Vibrio cholerae. Appl Environ Microbiol 2003 69: $1728-1738$

57. Goerke C, Wirtz C, Fluckiger U, Wolz C: Extensive phage dynamics in Staphylococcus aureus contributes to adaptation to the human host during infection. Mol Microbiol 2006 6 I:1673-1685.

58. Beres SB, Sylva GL, Barbian KD, Lei B, Hoff JS, Mammarella ND, Liu MY, Smoot JC, Porcella SF, Parkins LD, Campbell DS, Smith TM, McCormick JK, Leung DY, Schlievert PM, Musser JM: Genome sequence of a serotype M3 strain of group A Streptococcus : phage-encoded toxins, the high-virulence phenotype, and clone emergence. Proc Natl Acad Sci USA 2002, 99:10078-10083.

59. Green NM, Beres SB, Graviss EA, Allison JE, McGeer AJ, Vuopio-Varkila J, LeFebvre RB, Musser JM: Genetic diversity among type emm28 group A Streptococcus strains causing invasive infections and pharyngitis. I Clin Microbiol 2005, 43:4083-409|.

60. Fischetti VA: In vivo acquisition of prophage in Streptococcus pyogenes. Trends Microbiol 2007, I 5:297-300.

61. Bulder Cl: Induction of Petite Mutation and Inhibition of Synthesis of Respiratory Enzymes in Various Yeasts. Antonie Van Leeuwenhoek 1964, 30:1-9.

62. Rehberger TG, Glatz BA: Characterization of Propionibacterium plasmids. Appl Environ Microbiol 1990, 56:864-87I.

63. Doyle ME, Mazzotta AS, Wang T, Wiseman DW, Scott VN: Heat resistance of Listeria monocytogenes. I Food Prot 2001, 64:410-429.

64. Grif K, Hein I, Wagner M, Brandl E, Mpamugo O, McLauchlin J, Dierich MP, Allerberger F: Prevalence and characterization of Listeria monocytogenes in the feces of healthy Austrians. Wien Klin Wochenschr 2001, I I 3:737-742.

65. Sauders BD, Pettit D, Currie B, Suits P, Evans A, Stellrecht K, Dryja DM, Slate $D$, Wiedmann M: Low prevalence of Listeria monocytogenes in human stool. I Food Prot 2005, 68: I78-181.

66. Swaminathan B, Barrett TJ, Hunter SB, Tauxe RV: PulseNet: the molecular subtyping network for foodborne bacterial disease surveillance, United States. Emerg Infect Dis 200I, 7:382-389

67. Graves LM, Hunter SB, Ong AR, Schoonmaker-Bopp D, Hise K, Kornstein L, DeWitt WE, Hayes PS, Dunne E, Mead P, Swaminathan $\mathrm{B}$ : Microbiological aspects of the investigation that traced the 1998 outbreak of listeriosis in the United States to contaminated hot dogs and establishment of molecular subtypingbased surveillance for Listeria monocytogenes in the PulseNet network. I Clin Microbiol 2005, 43:2350-2355.

68. Graves LM, Swaminathan B: PulseNet standardized protocol for subtyping Listeria monocytogenes by macrorestriction and pulsed-field gel electrophoresis. Int J Food Microbiol 200I, 65:55-62.

69. Nightingale KK, Milillo SR, Ivy RA, Ho AJ, Oliver HF, Wiedmann M: Listeria monocytogenes F2365 carries several authentic muta- tions potentially leading to truncated gene products, including inIB, and demonstrates atypical phenotypic characteristics. J Food Prot 2007, 70:482-488

70. Bentley DR: Whole-genome re-sequencing. Curr Opin Genet Dev 2006, I 6:545-552.

7I. Read TD, Salzberg SL, Pop M, Shumway M, Umayam L, Jiang L, Holtzapple E, Busch JD, Smith KL, Schupp JM, Solomon D, Keim P, Fraser $\mathrm{CM}$ : Comparative genome sequencing for discovery of novel polymorphisms in Bacillus anthracis. Science 2002, 296:2028-2033.

72. Food Safety and Inspection Service - United States Department of Agriculture [http://www.fsis.usda.gov]

73. Loessner MJ, Schneider A, Scherer S: Modified Listeria bacteriophage lysin genes (ply) allow efficient overexpression and one-step purification of biochemically active fusion proteins. Appl Environ Microbiol 1996, 62:3057-3060.

74. 454 Newbler assembler v1.0.52.60 [http://www.454.com/ena bling-technology/the-software.asp]

75. Kamper J, Kahmann R, Bolker M, Ma LJ, Brefort T, Saville BJ, Banuett F, Kronstad JW, Gold SE, Muller O, Perlin MH, Wosten HA, de Vries R, Ruiz-Herrera J, Reynaga-Pena CG, Snetselaar K, McCann M, PerezMartin J, Feldbrugge M, Basse CW, Steinberg G, Ibeas Jl, Holloman W, Guzman P, Farman M, Stajich JE, Sentandreu R, Gonzalez-Prieto JM, Kennell JC, Molina L, Schirawski J, Mendoza-Mendoza A, Greilinger D, Munch K, Rossel N, Scherer M, Vranes M, Ladendorf O, Vincon V, Fuchs U, Sandrock B, Meng S, Ho EC, Cahill MJ, Boyce KJ, Klose J, Klosterman SJ, Deelstra HJ, Ortiz-Castellanos L, Li W, SanchezAlonso P, Schreier PH, Hauser-Hahn I, Vaupel M, Koopmann E, Friedrich G, Voss H, Schluter T, Margolis J, Platt D, Swimmer C, Gnirke A, Chen F, Vysotskaia V, Mannhaupt G, Guldener U, Munsterkotter M, Haase D, Oesterheld M, Mewes HW, Mauceli EW, DeCaprio D, Wade CM, Butler J, Young S, Jaffe DB, Calvo S, Nusbaum C, Galagan J, Birren BW: Insights from the genome of the biotrophic fungal plant pathogen Ustilago maydis. Nature 2006, 444:97-I0I.

76. CMR - J Craig Venter Institute [http://cmr.jcvi.org/]

77. Hall TA: BioEdit: a user-friendly biological sequence alignment editor and analysis program for Windows 95/98/NT. Nucl Acids Symp Ser 1999, 41:95-98.

78. Rozas J, Rozas R: DnaSP version 3: an integrated program for molecular population genetics and molecular evolution analysis. Bioinformatics 1999, I5: I74-175.

79. GENECONV - Software for recombination analysis [http:// www.math.wustl.edu/ sawyer]

80. Pathogen Tracker [http://www.pathogentracker.com]

81. Roberts A, Nightingale K, Jeffers G, Fortes E, Kongo JM, Wiedmann $M$ : Genetic and Phenotypic Characterization of Listeria monocytogenes lineage III. Microbiology 2006, I 52:685-693.

82. Conte MP, Petrone G, Di Biase AM, Ammendolia MG, Superti F, Seganti L: Acid tolerance in Listeria monocytogenes influences invasiveness of enterocyte-like cells and macrophage-like cells. Microb Pathog 2000, 29:137-I44.

Publish with Biomed Central and every scientist can read your work free of charge

"BioMed Central will be the most significant development for disseminating the results of biomedical research in our lifetime. "

Sir Paul Nurse, Cancer Research UK

Your research papers will be:

- available free of charge to the entire biomedical community

- peer reviewed and published immediately upon acceptance

- cited in PubMed and archived on PubMed Central

- yours - you keep the copyright
BioMedcentral 